\title{
Potential of garlic (Allium sativum) in lowering high blood pressure: mechanisms of action and clinical relevance
}

This article was published in the following Dove Press journal:

Integrated Blood Pressure Control

9 December 2014

Number of times this article has been viewed

\section{Karin Ried \\ Peter Fakler}

National Institute of Integrative Medicine, Melbourne, VIC, Australia
Correspondence: Karin Ried National Institute of Integrative Medicine, 21 Burwood Road, Hawthorn, VIC 3I22, Australia $\mathrm{Tel}+61399129545$

Fax +6I 398040513

Email karinried@niim.com.au

\begin{abstract}
Garlic supplements have shown promise in the treatment of uncontrolled hypertension, lowering blood pressure (BP) by about $10 \mathrm{mmHg}$ systolic and $8 \mathrm{mmHg}$ diastolic, similar to standard BP medication. Aged garlic extract, which contains $S$-allylcysteine as the bioactive sulfur compound, in particular is standardizable and highly tolerable, with little or no known harmful interaction when taken with other BP-reducing or blood-thinning medication. Here we describe biologically plausible mechanisms of garlic's BP-lowering effect. Garlic-derived polysulfides stimulate the production of the vascular gasotransmitter hydrogen sulfide $\left(\mathrm{H}_{2} \mathrm{~S}\right)$ and enhance the regulation of endothelial nitric oxide $(\mathrm{NO})$, which induce smooth muscle cell relaxation, vasodilation, and BP reduction. Several dietary and genetic factors influence the efficiency of the $\mathrm{H}_{2} \mathrm{~S}$ and NO signaling pathways and may contribute to the development of hypertension. Sulfur deficiency might play a part in the etiology of hypertension, and could be alleviated with supplementation of organosulfur compounds derived from garlic.
\end{abstract}

Keywords: garlic, $S$-allylcysteine, hydrogen sulfide $\left(\mathrm{H}_{2} \mathrm{~S}\right)$, nitric oxide (NO), redox signaling, hypertension

\section{Hypertension}

Hypertension, or chronically elevated blood pressure (BP) (systolic/diastolic BP [SBP/ $\mathrm{DBP}] \geq 140 / 90 \mathrm{mmHg}$ at the brachial artery), is a multifactorial condition implicated in the development and progression of cardiovascular disease. Hypertension is among the most important modifiable risk factors for cardiovascular disease. ${ }^{1}$

High BP affects nearly 1 billion people globally and about $30 \%$ of adults in Western countries. ${ }^{1}$ An estimated $70 \%$ heart attacks, strokes, and chronic heart failure are attributed to hypertension, leading to $37 \%$ of cardiovascular deaths in Western countries and $13.5 \%$ globally. ${ }^{2,3}$

Epidemiological studies have indicated a continuous association between BP and cardiovascular risk, suggesting that a reduction of high systolic BP $(\mathrm{SBP}>140 \mathrm{mmHg})$ by $20 \mathrm{mmHg}$ or a reduction of high diastolic $\mathrm{BP}(\mathrm{DBP}>90 \mathrm{mmHg})$ by $10 \mathrm{mmHg}$ is associated with a $50 \%$ risk reduction in developing cardiovascular disease. ${ }^{4}$

However, a steady increase of SBP with age is expected, whereas DBP tends to fall after middle age, with studies in elderly and middle aged populations suggesting a nonlinear J- or U-shaped relationship between BP and mortality.,

Therefore, appropriate assessment of an individual's BP status is important to guide whether antihypertension therapy is indicated or to avoid potential overtreatment. While office BP monitoring is most practical - with improved accuracy achieved after 5-10 minutes rest, repeated automated measures, ideally on 
both arms ${ }^{7,8}$ - sustained elevated readings using a 24-hour ambulatory BP monitoring (24-h ABPM) independently predict increased cardiovascular risk of $27 \%$ for every $10 \mathrm{mmHg}$ increase in 24-h ABPM SBP. ${ }^{9}$ Elevated nighttime BP, in particular, has been associated with increased risk of cardiovascular events including stroke and myocardial infarction. ${ }^{9}$

Twenty percent of individuals demonstrate white-coat hypertension, defined as elevated office BP but normotensive 24-h ABPM..$^{10}$ White-coat hypertension, however, has been associated with functional and structural cardiovascular abnormalities, including reduced arterial elasticity, left ventricular diastolic dysfunction, and enlarged arteries, similar to persistent hypertension. ${ }^{11}$ Therefore, treatment of individuals with white-coat hypertension may still be of benefit.

While management of BP in family practice has increased in the past 20 years, a large proportion (23\%) remain uncontrolled with persisting SBP $\geq 140 \mathrm{mmHg}$ or DBP $\geq 90 \mathrm{mmHg}$ independent of the treatment., ${ }^{72-14}$

Current guidelines for treatment of hypertension recommend starting monotherapy with any of the standard BP medication classes, including angiotensin-converting enzyme inhibitors, angiotensin II-receptor blockers, calcium-channel blockers, or diuretics in patients with uncomplicated hypertension. ${ }^{15,16}$ While guidelines are clear about when to consider treatment with BP medication, they are less clear about which BP medication class to start treatment with in patients with uncomplicated hypertension and no comorbidities; treatment is dependent on personal preference and experience of the treating doctor.

Guidelines further recommend follow-up after at least 6 weeks to check the effectiveness of treatment and potential change of BP medication regime by adding other BP medication classes, increasing dosage, or changing BP medication type, depending also on tolerability and potential side effects. ${ }^{15}$

Approximately $40 \%$ of hypertensive patients can achieve the target BP of $<140 / 90 \mathrm{mmHg}$ with monotherapy, independent of the type of antihypertensive medication used. About $40 \%$ require combination therapy with two agents, and $20 \%$ need to take three or more antihypertensive medications to achieve BP control. ${ }^{14,17}$ However, adverse reactions from antihypertensive medication may occur in a significant number of patients and are more likely when multiple drugs are prescribed. ${ }^{18}$ Adverse reactions include fatigue, dizziness, cough, headache, myalgia, angioedema, renal impairment, gastrointestinal upsets, hyperglycemia, and electrolyte disturbances. ${ }^{18}$

Long-term patient persistence with antihypertensive treatment is unsatisfactory, ${ }^{19,20}$ with only $44 \%$ of patients adhering to the treatment regimen in the long term. ${ }^{20,21}$ While physician-related barriers to effective management of uncontrolled hypertension, such as therapeutic inertia, contribute to this problem, ${ }^{22,23}$ patient motivation and satisfaction are equally important. ${ }^{24}$ Persistence varies with the type of medication ${ }^{20,21}$ and is associated with the severity and frequency of adverse events, ${ }^{18}$ as well as with the complexity of treatment. ${ }^{24}$

Several factors play a role in the development of hypertension, including genetic variability, lifestyle, and dietary influences. While genetic variability is estimated to contribute about $30 \%$ to individuals' BP profiles, ${ }^{25,26}$ lifestyle and dietary choices play an important role in BP modulation and control. ${ }^{13}$

Research suggests a body mass index (=weight/height ${ }^{2}$ ) between $18.5 \mathrm{~kg} / \mathrm{m}^{2}$ and $25 \mathrm{~kg} / \mathrm{m}^{2}$ to be the desired range for Caucasians. Reductions in SBP of 5-20 mmHg per $10 \mathrm{~kg}$ weight loss can be achieved in overweight hypertensives. ${ }^{13}$ In addition, 30 minutes of regular daily moderate aerobic exercise (eg, brisk walk) can reduce SBP by $4-9 \mathrm{mmHg},{ }^{13}$ while optimizing vitamin D levels (serum $>75 \mathrm{nmol} / \mathrm{L}$ ) can improve SBP by $3-4 \mathrm{mmHg}$ in hypertensives. ${ }^{27,28}$

Other lifestyle factors influencing BP include smoking, alcohol intake, and stress. Smoking cessation has been estimated to lead to a BP reduction of up to $10 \mathrm{mmHg}$ in hypertensives, ${ }^{29}$ alcohol consumption exceeding 1-2 standard drinks per day may influence BP by $2-4 \mathrm{mmHg},{ }^{13}$ and continuous stress and insufficient quality sleep may push the BP by up to $10 \mathrm{mmHg} .{ }^{30}$

Diet plays an important role in BP control, with the adoption of the dietary approaches to stop hypertension or a Mediterranean diet achieving BP reductions between $8 \mathrm{mmHg}$ and $14 \mathrm{mmHg}$ systolic in hypertensives. ${ }^{13,31}$ In addition, a meta-analysis including 13 trials ( $n=543$ hypertensives) of vitamin $\mathrm{C}$ intake of $500 \mathrm{mg}$ daily was associated with a reduction of $\mathrm{BP}$ of up to $5 \mathrm{mmHg}$ systolic. ${ }^{32}$ While moderation of sodium intake has been recommended, recent research suggests a greater importance of an adequate ratio between sodium and potassium $(\mathrm{NaCl} / \mathrm{KCl})$ intakes for optimal cardiovascular health. ${ }^{33,34}$

Other nutritional medical approaches to hypertension management include increased consumption of lycopene, mainly from tomato and watermelon, ${ }^{35}$ cocoa, ${ }^{36}$ and garlic, discussed here.

Interest in complementary and nutritional medicine has been increasing, with about $50 \%$ of Australians, including those with cardiovascular conditions, regularly using complementary therapies. ${ }^{37-40}$ As motivation to self-care may 
influence patient compliance, ${ }^{41}$ there is scope to explore the integration of effective nutritional and other complementary therapies in antihypertensive management.

\section{Garlic and hypertension}

Garlic (Allium sativum) has been used as a spice, food, and medicine for over 5,000 years, and is one of the earliest documented herbs utilized for the maintenance of health and treatment of disease..$^{42}$ In some of the oldest texts on medicine, eg, the Egyptian Ebers papyrus dating around 1500 BC and the sacred books of India, "the Vedas" (1200-200 BCE), garlic was recommended for many medicinal applications, including circulatory disorders. ${ }^{43}$ In ancient Greece, garlic was used as a diuretic, as recorded by Hippocrates, the father of modern medicine. ${ }^{44}$ In addition to its cardiovascular benefits, garlic has traditionally been used to strengthen the immune system and gastrointestinal health. ${ }^{42}$ Today, this intriguing herb is probably the most widely researched medicinal plant.

More recently, garlic has been shown to have BP-lowering properties. A meta-analysis including 20 clinical trials suggested garlic to be superior to placebo in lowering BP in hypertensive patients on average by $8-9 \mathrm{mmHg}$ in SBP and $6-7 \mathrm{mmHg}$ in DBP, $P<0.0001) .{ }^{45}$ Trials included in the metaanalysis were considered high quality, reporting adequate allocation concealment, randomization, double blinding, and low attrition. This reduction in BP reported in the meta-analysis is comparable to the BP-lowering effects of common antihypertensive medications. ${ }^{13,46}$ While garlic supplementation reduced BP significantly in hypertensive patients, it did not appreciably affect patients with normal $\mathrm{BP}^{45,47-49}$ In addition, response to and effectiveness of garlic supplementation appears to be dependent on individual genetic and dietary factors, with SBP reductions of up to $40 \mathrm{mmHg}$ in responders and a proportion of $25 \%-33 \%$ nonresponders, independent of garlic dosage, in a 3-month trial. ${ }^{50}$

\section{Types and components of garlic, tolerability, and safety}

Several types of garlic preparations are available, including raw and freshly cooked garlic, garlic oil, garlic powder, and aged garlic extract. Functional sulfur-containing components described in garlic include alliin, allicin, diallyl sulfide, diallyl disulfide, diallyl trisulfide, ajoene, and $S$-allylcysteine. ${ }^{51,52}$ Allicin, formed by enzymatic reaction from alliin, the main compound found in fresh raw garlic and garlic powder, is volatile and unstable. Allicin is destroyed by cooking, and has the potential to trigger intolerance, gastrointestinal complaints, and allergic reactions, ${ }^{53-55}$ and raw garlic taken in high doses can reduce red blood cell count. ${ }^{56}$ Garlic essential oil contains diallyl disulfide and diallyl trisulfide and no water-soluble allicin. Commercially available garlic oil preparations often include only a small amount of garlic essential oil in a vegetable oil base, complicating comparability and standardization of products..$^{53}$ In contrast, $S$-allylcysteine, the main active compound in aged garlic extract, is stable and standardizable, and has been found to be highly tolerable. ${ }^{36,51,54,55,57,58}$

The majority of clinical trials studying the effect of garlic on BP used either garlic powder or aged garlic extract. ${ }^{45,48}$ Side effects of garlic supplements, reported by about a third of the participants in these trials, were generally mild, and included burping, flatulence, and reflux in the first few weeks of the trial. ${ }^{47,50} \mathrm{~A}$ small number of the population (4\%-6\%) may experience more severe gastrointestinal disturbances with therapeutic dosages of garlic supplements. ${ }^{47,50,59,60}$ Lower tolerance of sulfur-containing foods such as garlic, onion, and leek may be reversed by supplementation with molybdenum and/or vitamin $\mathrm{B}_{12}$, often deficient in affected individuals. ${ }^{61,62}$

Despite the general advice, evidence is weak for garlic preparations causing harmful interactions if taken in addition to blood-thinning, blood-sugar-regulating, or anti-inflammatory medications. . $^{56,63,64}$ Physicians and patients need to be mindful, however, of a potentially harmful interaction of garlic with protease inhibitors in antiretroviral therapy. ${ }^{63}$ It is generally recommended that high doses (equivalent to $>4 \mathrm{~g}$ of fresh garlic or $3 \mathrm{mg}$ allicin) should be avoided in patients taking antithrombotic medications including warfarin, due to the antiplatelet properties of garlic. ${ }^{65}$ However, a trial using higher concentrations of aged garlic extract (10 mL/day, containing $14.7 \mathrm{mg} S$-allylcysteine) for patients on warfarin therapy found no increase in the incidence of hemorrhage compared with placebo. ${ }^{64}$

\section{Mechanisms for blood pressure- lowering effect of garlic}

Several mechanisms of action for the BP-lowering properties of organosulfur compounds in garlic have been postulated, including mediation of intracellular nitric oxide (NO) and hydrogen sulfide $\left(\mathrm{H}_{2} \mathrm{~S}\right)$ production as well as blockage of angiotensin-II production, which in turn promotes vasodilation and thus reduces the BP. ${ }^{66-71}$

The strongest evidence of and insights into the mechanisms of the BP-lowering effect of garlic supplementation involve endothelium-dependent vasodilation, and thus, this review 
will focus on the current knowledge of the physiological and biochemical processes within blood vessels.

\section{Vasorelaxation}

The relaxation of vascular smooth muscle cells is an element of the physiological mechanisms for lowering BP. Reduced responsiveness of blood vessels to relax from constriction following autonomic nervous, endocrine/prostanoid, or shear stress signaling is thought to be an important factor in the pathophysiology of hypertension, as indicated by experimental and clinical evidence. ${ }^{72}$

\section{NO, redox signaling, and the effect of garlic on hypertension}

The soluble gas NO is a well-known factor in the mechanism for acetylcholine-induced (parasympathetic) vasodilation. $\mathrm{NO}$ is synthesized from L-arginine by at least three isoforms of NO synthase (NOS) in the endothelium by endothelial NOS (eNOS), in nerve cells mainly by neuronal NOS, and in macrophages by inducible NOS. ${ }^{73}$ In some tissues and organs, including the heart, both eNOS and neuronal NOS are present.

Figure 1 illustrates vascular NO signaling pathways, including the effect of $\mathrm{NO}$ on vasodilation, and a potential influence of garlic organosulfur compounds.

eNOS-derived NO induces relaxation of smooth muscle cells and, thus, increased dilation of all types of blood vessels, via a guanylyl cyclase-dependent mechanism. ${ }^{73}$ Lack of NO production by eNOS is believed to be a major causal factor in the development of vascular dysfunction and hypertension..$^{74,75}$

eNOS, a highly regulated and complex enzyme, is inactive while bound to caveolin, and can be activated through calcium-responsive binding of calmodulin via hormonal or neuronal activation or shear stress-induced phosphorylation (Figure 1). The production of NO requires L-arginine as substrate and tetrahydrobiopterin $\left(\mathrm{BH}_{4}\right)$ as a cofactor. $\mathrm{BH}_{4}$ levels have been reported to decrease with aging and cardiovascular disease, and a lack of $\mathrm{BH}_{4}$ results in so-called eNOS uncoupling, resulting in the generation of high levels of superoxide $\left(\mathrm{O}_{2}^{-}\right)$and low levels of $\mathrm{NO}^{73}$

Redox signaling involves reversible oxidation-reduction of cysteinyl residues of proteins in cell membranes or within cells in response to the redox potential of the extracellular cysteine/cystine (CyS/Cys-S-S-Cys) pool. ${ }^{76}$ Increased plasma cystine concentration and/or oxidized plasma metabolites have been associated with increased prevalence of human pathologic conditions, including decreased flow-mediated dilation, reversible myocardial perfusion defects, and persistent atrial fibrillation. ${ }^{77}$ Thus, dietary factors affecting extracellular thiol/disulfide redox potential in human plasma could be important in cardiovascular disease. ${ }^{77}$

Oxidative stress, defined as "a disturbance in the pro-oxidant/antioxidant balance in favor of the former" has been an intensively researched field of inquiry in the past few decades. ${ }^{78}$ However, this definition has been challenged by a number of authors following recent advances in the understanding of redox signaling, and changes in the redox status of tissues have been shown to be part of cellular signal transduction. ${ }^{76,79-81}$

It has been postulated that hypertension, too, may be a result of a disruption in redox signaling rather than being caused by an imbalance of oxidants and antioxidants. ${ }^{82-84}$

It has been suggested that the redox status of the cellular milieu affects the activity of eNOS and thus modulates NO-dependent pathways in the endothelium. . $^{85,86}$

Aged garlic extract in cell culture prevented endothelial cells from "oxidative stress" by increasing cellular concentrations of thiol antioxidants, such as cysteine and glutathione (GSH) while shifting the ratio of oxidized GSH to reduced GSH (Figure 1). ${ }^{87}$

Moreover, aged garlic extract was shown to normalize NO output from endothelial cells by preventing the decline of $\mathrm{BH}_{4}$ levels. ${ }^{87}$ Relevant levels of $\mathrm{BH}_{4}$ prevent $\mathrm{NO}$ uncoupling and superoxide generation, which are thought to improve endothelial dysfunction, and potentially reducing the progression to atherosclerosis. ${ }^{87}$

In addition, $S$-glutathionylation of eNOS at two highly conserved cysteine residues reversibly decreases NOS activity with an increase in superoxide generation, resulting in impaired endothelium-dependent vasodilation. ${ }^{86}$ $S$-glutathionylation can be reversed, however, by thiol agents. $S$-glutathionylation of eNOS is thought to be a pivotal switch providing redox regulation of cellular signaling, endothelial function, and vascular tone.$^{86}$ Furthermore, while uncoupling of eNOS leads to potent inactivation of NO through its reaction with superoxide $\left(\mathrm{O}_{2}^{-}\right)$, this reaction forms the potent oxidant peroxynitrite $\left(\mathrm{ONOO}^{-}\right)$(Figure 1). Peroxinitrite has long been considered to be a highly toxic metabolic by-product, damaging biomolecules including proteins, lipids, and DNA. However, there have been new insights demonstrating that $\mathrm{ONOO}^{-}$is also involved in various signaling pathways, including a mechanism of vasodilation independent of cGMP. ${ }^{88}$

While NO clearly is an important signaling molecule, its overproduction has been implicated in various pathologies, 


\section{Nitric oxide signaling}

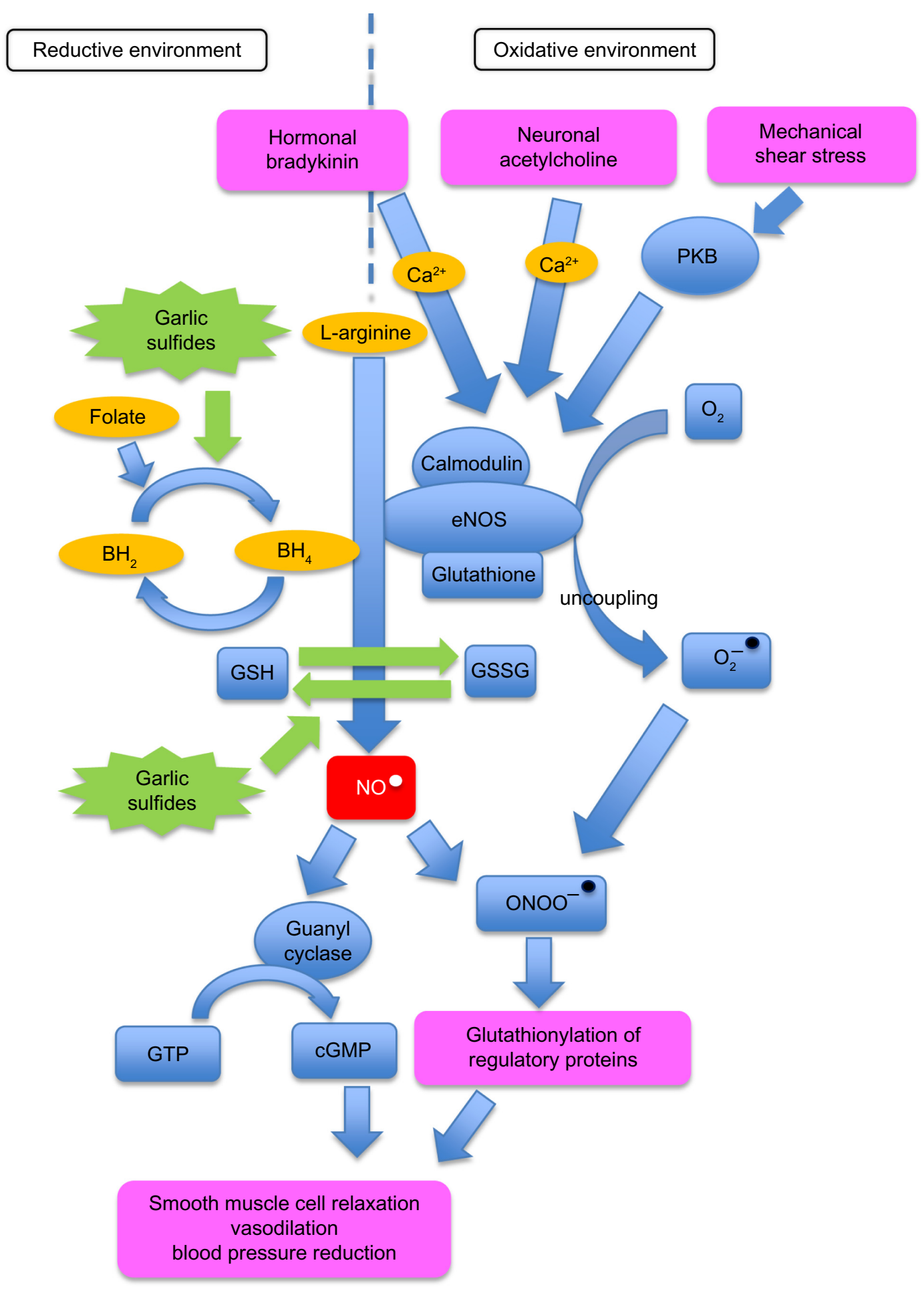

Figure I Effect of garlic on blood pressure via the NO pathway.

Notes: Blue rectangles illustrate metabolites, blue circles represent enzymes, orange circles are dietary cofactors, green star shapes are garlic and other organosulfurcontaining nutrients, red rectangle represents $\mathrm{NO}$, and purple rectangles denote direct and indirect influence of $\mathrm{NO}$ on vasodilation and blood pressure. NO pathway: in the presence of $\mathrm{BH}_{4}$, eNOS produces $\mathrm{NO}$, which triggers pathways leading to smooth muscle cell relaxation and vasodilation. eNOS uncoupling leads to the formation of $\mathrm{O}_{2}^{-}$. $\mathrm{NO}$ and $\mathrm{O}_{2}^{-}$combine to form $\mathrm{OONO}^{-}$, which rapidly reacts with thiols and tyrosine residues of proteins, which in turn, leads to vasodilation and $\mathrm{BP}$ reduction independent of cGMP. Garlic and other dietary organosulfides may play a role in the regulation of the NO signaling pathway by creating a more reductive environment and therefore supporting NO production.

Abbreviations: $\mathrm{BH}_{2}$, dihypdrobiopterin; $\mathrm{BH}_{4}$, tetrahydrobiopterin; $\mathrm{Ca}^{2+}$, calcium ion; cGMP, cyclic-guanosyl-monophosphate; GSSG, oxidized glutathione; eNOS, endothelialnitric-oxide-synthase; GSH, reduced free glutathione; GTP, guanosyl-tri-phosphate; $\mathrm{NO}$, nitric oxide (radical); ONOO, peroxynitrite; $\mathrm{O}_{2}$, oxygen; ${ }_{2}^{-}$, superoxide anion radical; PKB, protein kinase-B. 
including angiogenesis, mitochondrial dysfunction, and heart failure. ${ }^{89,90 ~ " N i t r o s a t i v e ~ s t r e s s " ~ m a y ~ c a u s e ~ h y p e r-n i t r o s y l a t i o n ~}$ of various regulatory enzymes leading to dysregulation of several cellular and physiological processes including inhibition of autophagy. ${ }^{91}$

Moreover, hyperproduction of NO may also lead to upregulation of mammalian target of rapamycin (mTOR), the central regulating molecule of the major signaling pathways for cell metabolism, growth, proliferation, and survival..$^{91}$ According to one theory of aging, the mTOR signaling pathway, driving developmental growth early in life, leads to age-related diseases through hyperfunction later in life. ${ }^{92}$ In fact, there is a growing list of physiological malfunctions linked to overstimulation of this NO-dependent signaling pathway, ranging from insulin resistance to neurodegenerative diseases to cancer, and even including hypertension itself. If $\mathrm{NO}$ enhances rather than inhibits mTOR signaling, there is cause for concern with pharmacological interventions increasing NO bioavailability, and potentially introducing unwanted effects.

The highly regulated NO signaling pathways described earlier depend on organic thiols and other sulfur-containing molecules, and thus may be impaired in sulfur deficiency. Garlic and other alliums, such as leek and onion, with their high content of polysulfides may help in providing the nutrients needed for maintaining or restoring optimum redox balances for a number of eNOS-dependent signaling pathways important in vascular relaxation.

\section{$\mathrm{H}_{2}$ S production and the effect of garlic on hypertension}

A second vascular gaseous signal transmitter is $\mathrm{H}_{2} \mathrm{~S} .{ }^{93}$ $\mathrm{H}_{2} \mathrm{~S}$ exists in micromolar concentrations in various mammalian tissues, including the brain, nervous system, vascular smooth muscle cells, and in the heart. ${ }^{93}$ Endogenous $\mathrm{H}_{2} \mathrm{~S}$ production is primarily the result of two enzymes: cystathionine- $\beta$-synthase (CBS) and cystathionine- $\gamma$-lyase (CSE), whereby the nonessential amino acid cysteine is metabolized by desulfuration, releasing sulfur in a reduced oxidation state and generating $\mathrm{H}_{2} \mathrm{~S}$. In addition, 3-mercaptopyruvate sulfur-transferase and cysteine aminotransferase localized to the endothelium of the thoracic aorta have also been reported to produce $\mathrm{H}_{2} \mathrm{~S}$ from cysteine and $\alpha$-ketoglutarate. ${ }^{94}$ Experiments with CSE knock-out rodents have found reduced levels of $\mathrm{H}_{2} \mathrm{~S}$ and hypertension. ${ }^{95}$ Also, spontaneously hypertensive rats have reduced expression of CSE in aortic tissues and lowered plasma levels of $\mathrm{H}_{2} \mathrm{~S} .{ }^{24,96,97}$
Figure 2 illustrates the $\mathrm{H}_{2} \mathrm{~S}$ production pathway, the connection to the methylation cycle and homocysteine (HCy), the effect of $\mathrm{H}_{2} \mathrm{~S}$ on vasodilation, and influence of garlic-derived polysulfides on this pathway.

The $\mathrm{H}_{2} \mathrm{~S}$-dependent BP-reducing effect is thought to be primarily mediated through sulfhydration of ATP-sensitive potassium $\left(\mathrm{K}_{\text {ATP }}\right)$ channels, which in turn leads to voltagesensitive channel opening and relaxation of vascular smooth muscle cells. ${ }^{98}$

However, other potassium channels may also be affected by $\mathrm{H}_{2} \mathrm{~S}$, and additional mechanisms have been suggested in determining the opening/closing of $\mathrm{K}^{+}$channels, including nitrosylation, and a possible cooperation between $\mathrm{H}_{2} \mathrm{~S}$ and NO..$^{98}$

While the relationship between $\mathrm{NO}$ and $\mathrm{H}_{2} \mathrm{~S}$ in controlling vascular relaxation is still unclear (eg, both upregulation and inhibition of eNOS by $\mathrm{H}_{2} \mathrm{~S}$ have been reported), ${ }^{99}$ there is convincing evidence that $\mathrm{H}_{2} \mathrm{~S}$ shares at least some of the vasorelaxing signaling role with $\mathrm{NO}$ and $\mathrm{H}_{2} \mathrm{~S}$ deficiency and therefore can contribute to vascular dysfunction including hypertension. ${ }^{84,93,94,100,101}$

\section{Nonenzymatic conversion of garlic- derived organic polysulfides to $\mathrm{H}_{2} \mathrm{~S}$}

In a series of elegant experiments, Benavides et $\mathrm{al}^{69}$ showed that garlic-derived polysulfides can produce $\mathrm{H}_{2} \mathrm{~S}$ under physiologically relevant $\mathrm{O}_{2}$ conditions in rat aortic tissue. They provided evidence for a mechanism involving reduced thiols. While it is unknown which garlic bioactives can release $\mathrm{H}_{2} \mathrm{~S}$ nonenzymatically, it has been hypothesized that the major bioactive $S$-allylcysteine found in aged garlic extract may also act as a substrate for the enzyme CSE to produce $\mathrm{H}_{2} \mathrm{~S} .{ }^{102}$

\section{$\mathrm{H}_{2} \mathrm{~S}$ deficiency and supplementation}

There is conflicting evidence about the potential age-related decline in vascular $\mathrm{H}_{2} \mathrm{~S}$ production, but any impairments of $\mathrm{H}_{2} \mathrm{~S}$ signaling may differ among tissues, with the liver being less susceptible to functional changes with age than less vital organs including the vasculature, which would be consistent with the triage theory of nutritional deficiencies. ${ }^{103,104}$

It is generally understood that most $\mathrm{H}_{2} \mathrm{~S}$ gets oxidized within mitochondria to thiosulfate and further to sulfate. Thiosulfate formed from $\mathrm{H}_{2} \mathrm{~S}$ through mitochondrial oxidation can undergo reduction and thus recycling by an enzymatic process dependent on dihydrolipoic acid (the reduced form of lipoic acid). ${ }^{105}$ While most $\mathrm{H}_{2} \mathrm{~S}$ oxidation occurs within mitochondria, extra-mitochondrial oxidation occurs by reactive oxygen species and reactive nitrogen species. ${ }^{106}$ Thus, 


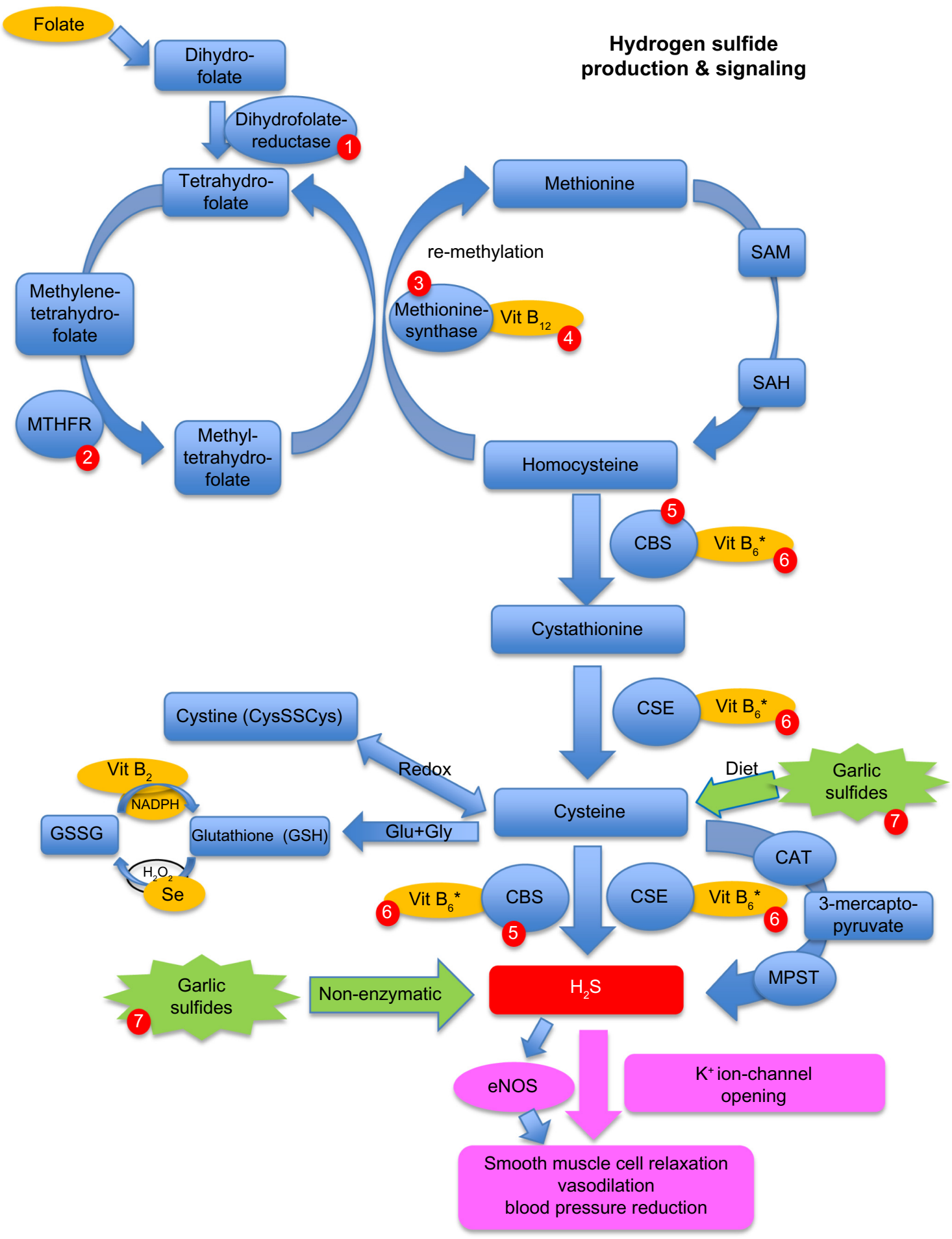

Figure 2 Effect of garlic on blood pressure via the hydrogen sulfide $\left(\mathrm{H}_{2} \mathrm{~S}\right)$ pathway, and influence of dietary and genetic factors on homocysteine levels.

Notes: Blue rectangles illustrate metabolites, blue circles represent enzymes, orange circles are dietary cofactors, green star shapes show garlic and other polysulfidecontaining nutrients, red rectangle indicates $\mathrm{H}_{2} \mathrm{~S}$, and purple rectangles represent direct and indirect influence of $\mathrm{H}_{2} \mathrm{~S}$ on vasodilation and blood pressure. Red circles $\mathrm{I}-7$ : Influence of dietary and genetic factors on $\mathrm{H}_{2} \mathrm{~S}$ pathway $\mathrm{I}=$ genetic polymorphism, homozygous for deleterious allele, leads to impaired folate metabolism. $2=$ common polymorphisms, some of which lead to increased homocysteine and decreased methylation and SAM levels; these respond well to folate supplementation. $3=$ genetic defects lead to increased homocysteine levels. $4=$ low Vit BI2 levels lead to increased homocysteine levels. $5=$ defect in CBS enzyme leads to increased homocysteine levels and reduced $\mathrm{H}_{2} \mathrm{~S}$ production. $6=$ low Vit $\mathrm{B}_{6}{ }^{*}$ levels may increase homocysteine levels and reduce $\mathrm{H}_{2} \mathrm{~S}$ production, and may respond to Vit $\mathrm{B}_{6}$ supplementation. $7=$ dietary intake of garlic polysulfides and thiosulfides can increase $\mathrm{H}_{2} \mathrm{~S}$ nonenzymatically, and may ameliorate genetic defects in the CBS enzyme, or dietary deficiencies in Vit $\mathrm{B}_{6}$ and/or the sulfur-containing amino acids cysteine and methionine.

Abbreviations: CAT, cysteine-amino-transferase; CBS, cystathionine- $\beta$-synthase; CSE, cystathionine- $\gamma$-lyase; CysSSCys, oxidized cysteine/cystine; eNOS, endothelial nitric oxide synthase; Glu, L-glutamic acid; Gly, glycine; GSSG, oxidized glutathione; GSH, reduced glutathione; $\mathrm{H}_{2} \mathrm{O}_{2}$, hydrogen peroxide; $\mathrm{K}^{+}$, potassium ion; MPST, mercapto pyruvate sulfur transferase; NADPH, nicotinamide adenine dinucleotide phosphate; MTHFR, methylene-tetra-hydro-folate reductase; SAH, S-adenosyl-homocysteine; SAM, S-adenosyl-methionine; Se, selenium; Vit $B_{6}{ }^{*}$, activated form of Vit $B_{6}=$ pyridoxal-phosphate; Vit $B_{2}$, vitamin $B_{2}$ (riboflavin); Vit $B_{12}$, vitamin $B_{12}$. 
tissue concentrations of $\mathrm{H}_{2} \mathrm{~S}$ can be expected to be lower in more oxidative environments. On the other hand, high concentrations of $\mathrm{H}_{2} \mathrm{~S}$ are toxic, and there is evidence that $\mathrm{H}_{2} \mathrm{~S}$ in high concentration itself causes formation of superoxide by inhibiting mitochondrial oxidative phosphorylation. This may be a possible negative feedback mechanism for limiting excessive $\mathrm{H}_{2} \mathrm{~S}$ concentrations. ${ }^{107}$ This suggests that the $\mathrm{H}_{2} \mathrm{~S}$ signaling pathway in vasorelaxation has a similar effect to NO signaling, without the potentially detrimental consequences of chronic overproduction of the gasotransmitter.

Approximately two cloves of garlic per meal have been estimated to release sufficient $\mathrm{H}_{2} \mathrm{~S}$ for maintaining the balanced blood vessel constriction. ${ }^{93}$ Other dietary $\mathrm{H}_{2} \mathrm{~S}$ donors besides alliums include sulforafane from crucifers, some fermented foods including "thousand year egg," and the infamous Asian durian fruit. ${ }^{108}$

\section{Garlic, hypertension, and elevated $\mathrm{HCy}$}

Many clinical and epidemiological studies have found a positive correlation between HCy plasma levels, endothelial dysfunction, and cardiovascular disorders. ${ }^{109-111}$ Conditions linked to endothelial dysfunction, such as acute ischemic stroke with greater arterial stiffness and stress-induced hypertension, have been reported in hyperhomocysteinemia (HHCy). ${ }^{112,113}$ Furthermore, serum concentrations of the sulfur-containing thiols $\mathrm{HCy}$, cysteine, and GSH have shown to be independently associated with cardiovascular risk scores at the population level. ${ }^{114}$ However, whether elevated levels of HCy are primary or secondary risk factors for cardiovascular disease is less clear. ${ }^{115,116}$ There is a clear negative correlation between elevated HCy levels and brain and cognitive function. ${ }^{117,118}$

Elevated levels of HCy might be a consequence of impaired endothelial production of $\mathrm{H}_{2} \mathrm{~S} .{ }^{119}$ The transformation of $\mathrm{HCy}$ into cysteine is catalyzed by the enzymes CBS and CSE as part of the transsulfuration pathway (Figure 2). ${ }^{94,120} \mathrm{CBS}$ and CLE are also among the few enzymes in mammals with the capacity to produce $\mathrm{H}_{2} \mathrm{~S}$. The chemical reaction facilitated by CBS is a vitamin-B ${ }_{6}$-(pyridoxal-phosphate)dependent condensation of either serine or cysteine and $\mathrm{HCy} .{ }^{119} \mathrm{CBS}$ is the rate-limiting enzyme necessary for terminal removal of $\mathrm{HCy}$. Deficiencies in CBS activity caused by genetic mutations of the $C B S$ gene are the most frequent cause of familial HHCy. ${ }^{121}$ There are at least 153 mutations known to exist in the $C B S$ gene, with several significantly reducing CBS activity. ${ }^{121}$ These genetic $C B S$ deficiencies can be divided into two major allelic variance types: vita$\min \mathrm{B}_{6}$ responsive and vitamin $\mathrm{B}_{6}$ nonresponsive. ${ }^{122,123}$ Individuals with some of these genetic variants are likely to have both decreased production of $\mathrm{H}_{2} \mathrm{~S}$ and elevated levels of $\mathrm{HCy}$. While cases with a vitamin $\mathrm{B}_{6}$-responsive variant can be treated with ongoing $B_{6}$ therapy, cases affected by vitamin $\mathrm{B}_{6}$ nonresponsive variants continue to have impaired production of $\mathrm{H}_{2} \mathrm{~S}$, but may benefit from supplementation with nutritional $\mathrm{H}_{2} \mathrm{~S}$ donors, such as garlic. Thus, consumption of garlic, which can produce $\mathrm{H}_{2} \mathrm{~S}$ nonenzymatically, ${ }^{69}$ may benefit conditions related to impaired production of $\mathrm{H}_{2} \mathrm{~S}$, such as hypertension, even without lowering $\mathrm{HCy}$.

On the other hand, in carriers of a deficient methylenetetra-hydro-folate-reductase (MTHFR) variant, elevated HCy due to impaired remethylation may cause increased levels of $\mathrm{H}_{2} \mathrm{~S}$, which has been linked to an increase in platelet activation and may contribute to the development of recurrent arterial and venous thrombosis in these patients. ${ }^{124}$ It is therefore possible that supplementation with $\mathrm{H}_{2} \mathrm{~S}$-boosting nutrients, such as garlic, may be counterproductive in individuals with MTHFR deficiency.

Furthermore, both CBS enzyme deficiencies and deficiencies in sulfur-containing amino acids (especially methionine and cysteine) are known to result in low levels of GSH, which plays important roles in cellular redox status and signaling. Elevated levels of $\mathrm{HCy}$ and decreased levels of cysteine and GSH have been found in a population with a low dietary intake of protein and sulfur-containing amino acids, and might be regarded as biomarkers of sulfur deficiency. ${ }^{125}$ A correlation between low red blood cell GSH and increased plasma HCy has been linked to an increased incidence of hypertension. ${ }^{126}$ Garlic, with its high content of sulfur compounds (including $S$-allylcysteine), has the potential to alleviate sulfur deficiencies caused by low-protein diets, which may also influence BP in these individuals.

Garlic's potential effect on HCy levels has been reported in a small clinical trial of atherosclerosis patients randomized to aged garlic extract $(P=0.08) .{ }^{127}$ Additionally, in an animal model of HHCy, induced by a severely folate-depleted diet in rats, aged garlic extract decreased plasma HCy concentrations by $30 \% .{ }^{128}$ In contrast, elevated levels of HCy caused by mild folate deficiency did not change significantly by garlic supplementation. ${ }^{128}$

Thus, garlic may have an effect on HCy metabolism independent of the effect of $\mathrm{B}$ vitamins in addition to boosting $\mathrm{H}_{2} \mathrm{~S}$ production. 


\section{Renin-angiotensin-aldosterone system and the effect of garlic on hypertension}

Other potential mechanisms of action for garlic's effect on hypertension have been proposed, including the potential of garlic blocking angiotensin-II production by inhibition of the angiotensin-converting-enzyme (ACE), as suggested in a number of cell culture and animal studies. ${ }^{67,71,129} \mathrm{ACE}$ is a component in the renin-angiotensin-aldosterone system, and inhibitors of ACE are used as standard BP-controlling pharmaceuticals. However, animal and cell culture experiments were mainly conducted with fresh garlic compounds, containing allicin ( $S$-allyl-cysteine sulfoxide), which has a very low sustained bioavailability in human tissues. ${ }^{55}$ Therefore, the antihypertensive effect of garlic via the proposed angiotensinconverting enzyme inhibitor mechanism seems less plausible than its $\mathrm{H}_{2} \mathrm{~S}$-stimulating and NO-regulating properties.

\section{Conclusion}

Garlic, particularly in the form of the standardizable and highly tolerable aged garlic extract, has the potential to lower BP in hypertensive individuals similarly to standard BP medication, via biologically plausible mechanisms of action. Primarily, polysulfides in garlic have the potential to upregulate $\mathrm{H}_{2} \mathrm{~S}$ production via enzymatic and nonenzymatic pathways, which promote vasodilation and $\mathrm{BP}$ reduction.

Several dietary and genetic factors, including folate, vitamin $\mathrm{B}_{6}$, and vitamin $\mathrm{B}_{12}$ deficiency, and known genetic variants of the MTHFR and $C B S$ genes, influence the efficiency of $\mathrm{H}_{2} \mathrm{~S}$ production, and could be important contributors to hypertension in these individuals, which may also explain individual responsiveness to garlic supplementation seen in clinical trials.

Polysulfides in garlic may also influence regulation of NO redox signaling pathways, including NO-mediated vasodilation and reduction of BP. Future clinical trials could explore the potential influence of nutritional status and genetic factors on the individual's responsiveness to garlic therapy for hypertension.

\section{Disclosure}

The authors report no conflicts of interest in this work.

\section{References}

1. World Heart Federation. Fact Sheet: Cardiovascular Disease Risk Factors. Geneva: World Heart Federation; 2012. Available from: http://www. world-heart-federation.org/press/fact-sheets/cardiovascular-disease-riskfactors/. Accessed November 12, 2014.
2. Lawes CM, Vander Hoorn S, Rodgers A. Global burden of bloodpressure-related disease, 2001. Lancet. 2008;371(9623):1513-1518.

3. Martiniuk AL, Lee CM, Lawes CM, et al. Hypertension: its prevalence and population-attributable fraction for mortality from cardiovascular disease in the Asia-Pacific region. J Hypertens. 2007;25(1):73-79.

4. Lewington S, Clarke R, Qizilbash N, Peto R, Collins R. Age-specific relevance of usual blood pressure to vascular mortality: a meta-analysis of individual data for one million adults in 61 prospective studies. Lancet. 2002;360(9349):1903-1913.

5. Denker MG, Cohen DL. What is an appropriate blood pressure goal for the elderly: review of recent studies and practical recommendations. Clin Interv Aging. 2013;8:1505.

6. Bangalore S, Messerli FH, Wun CC, et al. J-curve revisited: an analysis of blood pressure and cardiovascular events in the Treating to New Targets (TNT) Trial. Eur Heart J. 2010;31(23):2897-2908.

7. Briganti EM, Shaw JE, Chadban SJ, et al. Untreated hypertension among Australian adults: the 1999-2000 Australian Diabetes, Obesity and Lifestyle Study. Med J Aust. 2003;179(3):135-139.

8. Myers MG. The great myth of office blood pressure measurement J Hypertens. 2012;30(10):1894-1898.

9. Conen D, Bamberg F. Noninvasive 24-h ambulatory blood pressure and cardiovascular disease: a systematic review and meta-analysis. J Hypertens. 2008;26(7):1290-1299.

10. Fagard RH, Cornelissen VA. Incidence of cardiovascular events in whitecoat, masked and sustained hypertension versus true normotension: a meta-analysis. $J$ Hypertens. 2007;25(11):2193-2198.

11. Glen SK, Elliott HL, Curzio JL, Lees KR, Reid JL. White-coat hypertension as a cause of cardiovascular dysfunction. Lancet. 1996;348(9028): 654-657.

12. Centers for Disease Control and Prevention. Vital signs: prevalence, treatment, and control of hypertension - United States, 1999-2002 and 2005-2008. MMWR Morb Mortal Wkly Rep. 2011;60(4):103.

13. Chobanian AV, Bakris GL, Black HR, et al. The 7th report of the joint national committee on prevention detection evaluation and treatment of high blood pressure. JAMA. 2003;289(19):2560-2572.

14. Calhoun DA, Jones D, Textor S, et al. Resistant hypertension: diagnosis, evaluation, and treatment a scientific statement from the American Heart Association Professional Education Committee of the Council for High Blood Pressure Research. Hypertension. 2008;51(6):1403-1419.

15. National Heart Foundation of Australia (National Blood Pressure and Vascular Disease Advisory Committee). Guide to management of hypertension 2008. Updated Dec 2010.

16. Mancia G, Fagard R, Narkiewicz K, et al. 2013 ESH/ESC Guidelines for the management of arterial hypertension: the Task Force for the management of arterial hypertension of the European Society of Hypertension (ESH) and of the European Society of Cardiology (ESC). J Hypertens. 2013;31(7):1281-1357.

17. Hobbs F, Irwin P, Rubner J. Evidence-based treatment of hypertension: what's the role of angiotensin II receptor blockers? $\mathrm{Br} J$ Cardiol. 2005; 12(1):65-70.

18. Olsen H, Klemetsrud T, Stokke HP, Tretli S, Westheim A. Adverse drug reactions in current antihypertensive therapy: a general practice survey of 2586 patients in Norway. Blood Press. 1999;8(2):94-101.

19. Hasford J, Mimran A, Simons WR. A population-based European cohort study of persistence in newly diagnosed hypertensive patients. $J$ Hum Hypertens. 2002;16(8):569-575.

20. Simons LA, Ortiz M, Calcino G. Persistence with antihypertensive medication: Australia-wide experience, 2004-2006. Med J Aust. 2008;188(4):224-227.

21. Caro JJ, Speckman JL, Salas M, Raggio G, Jackson J. Effect of initial drug choice on persistence with antihypertensive therapy: the importance of actual practice data. Can Med Assoc J. 1999;160(1):41-46.

22. Okonofua EC, Simpson KN, Jesri A, Rehman SU, Durkalski VL, Egan BM. Therapeutic inertia is an impediment to achieving the Healthy People 2010 blood pressure control goals. Hypertension. 2006;47(3):345-351. 
23. Oliveria SA, Lapuerta P, McCarthy BD, L'Italien GJ, Berlowitz DR, Asch SM. Physician-related barriers to the effective management of uncontrolled hypertension. Arch Intern Med. 2002;162(4):413-420.

24. Burnier M. Long-term compliance with antihypertensive therapy: another facet of chronotherapeutics in hypertension. Blood Press Monit. 2000;5(Suppl 1):S31-S34.

25. Korner PI. Essential Hypertension and its Causes: Neural and NonNeural Mechanisms. Oxford: Oxford University Press; 2007.

26. Mo R, Omvik P, Lund-Johansen P. The Bergen blood pressure study: offspring of two hypertensive parents have significantly higher blood pressures than offspring of one hypertensive and one normotensive parent. J Hypertens. 1995;13(12 pt 2):1614-1617.

27. Witham MD, Nadir MA, Struthers AD. Effect of vitamin D on blood pressure: a systematic review and meta-analysis. J Hypertens. 2009;27(10): 1948.

28. Souberbielle JC, Body JJ, Lappe JM, et al. Vitamin D and musculoskeletal health, cardiovascular disease, autoimmunity and cancer: recommendations for clinical practice. Autoimmun Rev. 2010;9(11):709-715.

29. Groppelli A, Giorgi DM, Omboni S, Parati G, Mancia G. Persistent blood pressure increase induced by heavy smoking. J Hypertens. 1992;10(5):495-499.

30. McCraty R, Atkinson M, Tomasino D. Impact of a workplace stress reduction program on blood pressure and emotional health in hypertensive employees. J Altern Complement Med. 2003;9(3):355-369.

31. Eckel RH, Jakicic JM, Ard JD, et al. 2013 AHA/ACC guideline on lifestyle management to reduce cardiovascular risk: a report of the American College of Cardiology/American Heart Association Task Force on Practice Guidelines. J Am Coll Cardiol. 2014;63(25 pt B):2960-2984.

32. Juraschek SP, Guallar E, Appel LJ, Miller ER 3rd. Effects of vitamin C supplementation on blood pressure: a meta-analysis of randomized controlled trials. Am J Clin Nutr. 2012;95(5):1079-1088.

33. Mente A, O'Donnell MJ, Rangarajan S, et al. Association of urinary sodium and potassium excretion with blood pressure. $N$ Engl J Med. 2014;371(7):601-611.

34. O'Donnell M, Mente A, Rangarajan S, et al. Urinary sodium and potassium excretion, mortality, and cardiovascular events. $N$ Engl $J$ Med. 2014;371(7):612-623.

35. Ried K, Fakler P. Protective effect of lycopene on serum cholesterol and blood pressure: meta-analyses of intervention trials. Maturitas. 2011;68(4):299-310.

36. Ried K, Sullivan TR, Fakler P, Frank OR, Stocks NP. Effect of chocolate on blood pressure. Cochrane Database Syst Rev. 2012;8: CD008893.

37. MacLennan AH, Myers SP, Taylor AW. The continuing use of complementary and alternative medicine in South Australia: costs and beliefs in 2004. Med J Aust. 2006;184(1):27-31.

38. Harris P, Rees R. The prevalence of complementary and alternative medicine use among the general population: a systematic review. Complement Ther Med. 2000;8(2):88-96.

39. Yeh GY, Davis RB, Phillips RS. Use of complementary therapies in patients with cardiovascular disease. Am J Cardiol. 2006;98(5): 673-680.

40. Lin MC, Nahin R, Gershwin ME, Longhurst JC, Wu KK. State of complementary and alternative medicine in cardiovascular, lung, and blood research executive summary of a workshop. Circulation. 2001;103(16):2038-2041

41. Gohar F, Greenfield SM, Beevers DG, Lip GY, Jolly K. Self-care and adherence to medication: a survey in the hypertension outpatient clinic. BMC Complement Altern Med. 2008;8:4.

42. Rivlin RS. Historical perspective on the use of garlic. J Nutr. 2001; 131(Suppl 3):951S-954S.

43. Petrovska BB, Cekovska S. Extracts from the history and medical properties of garlic. Pharmacogn Rev. 2010;4(7):106.

44. Moyers SB. Garlic in Health, History, and World Cuisine. St Petersburg: Suncoast Press; 1996.

45. Ried K. Effect of garlic on blood pressure, serum cholesterol and immunity: updated meta-analyses and review. J Nutr. 2014.
46. McInnes GT. Lowering blood pressure for cardiovascular risk reduction. J Hypertens Suppl. 2005;23(1):S3-S8.

47. Ried K, Frank OR, Stocks NP. Aged garlic extract lowers blood pressure in patients with treated but uncontrolled hypertension: a randomised controlled trial. Maturitas. 2010;67:144-150.

48. Ried K, Frank OR, Stocks NP, Fakler P, Sullivan T. Effect of garlic on blood pressure: a systematic review and meta-analysis. $B M C$ Cardiovasc Disord. 2008;8:13.

49. Reinhart KM, Coleman CI, Teevan C, Vachhani P, White CM. Effects of garlic on blood pressure in patients with and without systolic hypertension: a meta-analysis. Ann Pharmacother. 2008;42(12):1766-1771.

50. Ried K, Frank OR, Stocks NP. Aged garlic extract reduces blood pressure in hypertensives: a dose-response trial. Eur J Clin Nutr. 2013;67:64-70.

51. Amagase H. Clarifying the real bioactive constituents of garlic. J Nutr. 2006;136(Suppl 3):716S-725S

52. Yun HM, Ban JO, Park KR, et al. Potential therapeutic effects of functionally active compounds isolated from garlic. Pharmacol Ther. 2014;142(2):183-195.

53. Amagase H, Petesch BL, Matsuura H, Kasuga S, Itakura Y. Intake of garlic and its bioactive components. J Nutr. 2001;131(3):955S-962S.

54. Lawson LD, Wang ZJ. Low allicin release from garlic supplements: a major problem due to the sensitivities of alliinase activity. J Agric Food Chem. 2001;49(5):2592-2599.

55. Lawson LD, Gardner CD. Composition, stability, and bioavailability of garlic products used in a clinical trial. JAgric Food Chem. 2005;53(16): 6254-6261

56. Harauma A, Moriguchi T. Aged garlic extract improves blood pressure in spontaneously hypertensive rats more safely than raw garlic. $J$ Nutr. 2006;136(Suppl 3):769S-773S.

57. Kodera Y, Suzuki A, Imada O, et al. Physical, chemical, and biological properties of s-allylcysteine, an amino acid derived from garlic. JAgric Food Chem. 2002;50(3):622-632.

58. Hoshino T, Kashimoto N, Kasuga S. Effects of garlic preparations on the gastrointestinal mucosa. J Nutr. 2001;131(3s):1109S-1113S.

59. Beck E, Gruenwald J. Allium sativum in der Stufentherapie der Hyperlipidaemie. Med Welt. 1993;44:516-520.

60. Borrelli F, Capasso R, Izzo AA. Garlic (Allium sativum L.): adverse effects and drug interactions in humans. Mol Nutr Food Res. 2007; 51(11):1386-1397.

61. Waring RH, Klovrza LZ, Harris RM. Diet and individuality in detoxification. J Nutr Environ Med. 2007;16(2):95-105.

62. Meletis CD. Cleansing of the human body. A daily essential process. Altern Complement Ther. 2001;7(4):196-202.

63. Izzo AA, Ernst E. Interactions between herbal medicines and prescribed drugs: an updated systematic review. Drugs. 2009;69(13): 1777-1798.

64. Macan H, Uykimpang R, Alconcel M, et al. Aged garlic extract may be safe for patients on warfarin therapy. J Nutr. 2006;136(Suppl 3):793S-795S.

65. Braun L, Cohen M. Herbs and Natural Supplements: An EvidenceBased Guide. Chatswood: Elsevier; 2007.

66. Al-Qattan KK, Thomson M, Al-Mutawa'a S, Al-Hajeri D, Drobiova H, Ali M. Nitric oxide mediates the blood-pressure lowering effect of garlic in the rat two-kidney, one-clip model of hypertension. $J$ Nutr. 2006;136(Suppl 3):774S-776S.

67. Sharifi AM, Darabi R, Akbarloo N. Investigation of antihypertensive mechanism of garlic in $2 \mathrm{~K} 1 \mathrm{C}$ hypertensive rat. $J$ Ethnopharmacol. 2003;86(2-3):219-224.

68. Morihara N, Sumioka I, Moriguchi T, Uda N, Kyo E. Aged garlic extract enhances production of nitric oxide. Life Sci. 2002;71(5):509-517.

69. Benavides GA, Squadrito GL, Mills RW, et al. Hydrogen sulfide mediates the vasoactivity of garlic. Proc Natl Acad Sci U S A. 2007; 104(46): 17977-17982.

70. Chuah SC, Moore PK, Zhu YZ. S-allylcysteine mediates cardioprotection in an acute myocardial infarction rat model via a hydrogen sulfide-mediated pathway. Am J Physiol Heart Circ Physiol. 2007;293(5):H2693-H2701. 
71. Shouk R, Abdou A, Shetty K, Sarkar D, Eid A. Mechanisms underlying the antihypertensive effects of garlic bioactives. Nutr Res. 2014;34:106-115.

72. Kirby BS, Crecelius AR, Voyles WF, Dinenno FA. Vasodilatory responsiveness to adenosine triphosphate in ageing humans. J Physiol. 2010;588(20):4017-4027.

73. Förstermann U, Sessa WC. Nitric oxide synthases: regulation and function. Eur Heart J. 2012;33(7):829-837.

74. Panza JA, García CE, Kilcoyne CM, Quyyumi AA, Cannon RO. Impaired endothelium-dependent vasodilation in patients with essential hypertension evidence that nitric oxide abnormality is not localized to a single signal transduction pathway. Circulation. 1995;91(6): 1732-1738.

75. Montezano AC, Touyz RM. Reactive oxygen species and endothelial function-role of nitric oxide synthase uncoupling and Nox family nicotinamide adenine dinucleotide phosphate oxidases. Basic Clin Pharmacol Toxicol. 2012;110(1):87-94.

76. Jones DP. Redefining oxidative stress. Antioxid Redox Signal. 2006; 8(9-10):1865-1879.

77. Jones DP, Park Y, Gletsu-Miller N, et al. Dietary sulfur amino acid effects on fasting plasma cysteine/cystine redox potential in humans. Nutrition. 2011;27(2):199-205.

78. Sies H. Oxidative stress: oxidants and antioxidants. Exp Physiol. 1997;82(2):291-295.

79. Linnane AW, Kios M, Vitetta L. Healthy aging: regulation of the metabolome by cellular redox modulation and prooxidant signaling systems: the essential roles of superoxide anion and hydrogen peroxide. Biogerontology. 2007;8(5):445-467.

80. Finkel T. Signal transduction by reactive oxygen species. J Cell Biol 2011;194(1):7-15.

81. Halliwell B. Free radicals and antioxidants - quo vadis? Trends Pharmacol Sci. 2011;32(3):125-130.

82. Lee MY, Griendling KK. Redox signaling, vascular function, and hypertension. Antioxid Redox Signal. 2008;10(6):1045-1059.

83. Touyz RM, Briones AM. Reactive oxygen species and vascular biology: implications in human hypertension. Hypertens Res. 2011;34(1): 5-14.

84. Majzunova M, Dovinova I, Barancik M, Chan J. Redox signaling in pathophysiology of hypertension. J Biomed Sci. 2013;20(1):69.

85. Sugiyama T, Michel T. Thiol-metabolizing proteins and endothelial redox state: differential modulation of eNOS and biopterin pathways. Am J Physiol (Cell Physiol). 2010;22(1):H194.

86. Chen C-A, Wang T-Y, Varadharaj S, et al. S-glutathionylation uncouples eNOS and regulates its cellular and vascular function. Nature. 2010;468(7327):1115-1118.

87. Weiss N, Papatheodorou L, Morihara N, Hilge R, Ide N. Aged garlic extract restores nitric oxide bioavailability in cultured human endothelial cells even under conditions of homocysteine elevation. J Ethnopharmacol. 2013;145(1):162-167.

88. Cohen RA, Adachi T. Nitric oxide induced vasodilatation: regulation by physiologic S-glutathiolation and pathologic oxidation of the sarcoplasmic endoplasmic reticulum calcium ATPase. Trends Cardiovasc Med. 2006;16(4):109-114.

89. Foster MW, Hess DT, Stamler JS. Protein S-nitrosylation in health and disease: a current perspective. Trends Mol Med. 2009;15(9): 391-404.

90. Pall ML. The NO/ONOO-cycle as the central cause of heart failure. Int J Mol Sci. 2013;14(11):22274-22330.

91. Sarkar S, Korolchuk VI, Renna M, et al. Complex inhibitory effects of nitric oxide on autophagy. Mol Cell. 2011;43(1):19-32.

92. Blagosklonny MV. Answering the ultimate question "what is the proximal cause of aging?". Aging (Albany NY). 2012;4(12):861.

93. Wang R. Physiological implications of hydrogen sulfide: a whiff exploration that blossomed. Physiol Rev. 2012;92(2):791-896.

94. Zhang Y, Tang Z-H, Ren Z, et al. Hydrogen sulfide, the next potent preventive and therapeutic agent in aging and age-associated diseases. Mol Cell Biol. 2013;33(6):1104-1113.
95. Lake-Bruse KD, Faraci FM, Shesely EG, Maeda N, Sigmund CD, Heistad DD. Gene transfer of endothelial nitric oxide synthase (eNOS) in eNOS-deficient mice. Am J Physiol (Heart Circ Physiol). 1999;277(2):H770-H776.

96. Yan H, Du J, Tang C. The possible role of hydrogen sulfide on the pathogenesis of spontaneous hypertension in rats. Biochem Biophys Res Commun. 2004;313(1):22-27.

97. Zhao X, Zhang L-K, Zhang C-Y, et al. Regulatory effect of hydrogen sulfide on vascular collagen content in spontaneously hypertensive rats. Hypertens Res. 2008;31(8):1619-1630.

98. Jiang B, Tang G, Cao K, Wu L, Wang R. Molecular mechanism for H2S-induced activation of KATP channels. Antioxid Redox Signal. 2010;12(10):1167-1178.

99. Kolluru GK, Shen X, Kevil CG. A tale of two gases: NO and H2S, foes or friends for life? Redox Biol. 2013;1(1):313-318.

100. Predmore BL, Lefer DJ, Gojon G. Hydrogen sulfide in biochemistry and medicine. Antioxid Redox Signal. 2012;17(1):119-140.

101. Kashfi K, Olson KR. Biology and therapeutic potential of hydrogen sulfide and hydrogen sulfide-releasing chimeras. Biochem Pharmacol. 2013;85(5):689-703.

102. Chuah SC, Moore PK, Zhu YZ. S-allylcysteine mediates cardioprotection in an acute myocardial infarction rat model via a hydrogen sulfide-mediated pathway. Am J Physiol Heart Circ Physiol. 2007;293(5):H2693-H2701.

103. Predmore BL, Alendy MJ, Ahmed KI, Leeuwenburgh C, Julian D. The hydrogen sulfide signaling system: changes during aging and the benefits of caloric restriction. Age. 2010;32(4):467-481.

104. Ames BN. Low micronutrient intake may accelerate the degenerative diseases of aging through allocation of scarce micronutrients by triage. Proc Natl Acad Sci U S A. 2006;103(47):17589-17594.

105. Yoshinori M, Norihiro S, Yuka K, Noriyuki N, Yuki O, Hideo K. Thioredoxin and dihydrolipoic acid are required for 3-mercaptopyruvate sulfurtransferase to produce hydrogen sulfide. Biochem J. 2011;439(3): $479-485$

106. Nikolaidis MG, Jamurtas AZ. Blood as a reactive species generator and redox status regulator during exercise. Arch Biochem Biophys. 2009;490(2):77-84.

107. Olson KR. A practical look at the chemistry and biology of hydrogen sulfide. Antioxid Redox Signal. 2012;17(1):32-44.

108. Wang R. Is H2S a stinky remedy for atherosclerosis? Arterioscler Thromb Vasc Biol. 2009;29(2):156-157.

109. Schalinske KL, Smazal AL. Homocysteine imbalance: a pathological metabolic marker. Adv Nutr. 2012;3(6):755-762.

110. Moat SJ, McDowell IF. Homocysteine and endothelial function in human studies. Semin Vasc Med. 2005;5(2):172-182.

111. Weiss N, Keller C, Hoffmann U, Loscalzo J. Endothelial dysfunction and atherothrombosis in mild hyperhomocysteinemia. Vasc Med. 2002;7(3):227-239.

112. Tayama J, Munakata M, Yoshinaga K, Toyota T. Higher plasma homocysteine concentration is associated with more advanced systemic arterial stiffness and greater blood pressure response to stress in hypertensive patients. Hypertens Res. 2006;29(6):403.

113. Mizrahi EH, Noy S, Sela B-A, Fleissig Y, Arad M, Adunsky A. Further evidence of interrelation between homocysteine and hypertension in stroke patients: a cross-sectional study. Isr Med Assoc J. 2003;5(11):791-794.

114. Mangoni AA, Zinellu A, Carru C, Attia JR, McEvoy M. Serum thiols and cardiovascular risk scores: a combined assessment of transsulfuration pathway components and substrate/product ratios. J Transl Med. 2013;11(1):1-9.

115. Christen WG, Ajani UA, Glynn RJ, Hennekens CH. Blood levels of homocysteine and increased risks of cardiovascular disease: causal or casual? Arch Intern Med. 2000;160(4):422-434.

116. Clarke R, Bennett DA, Parish S, et al. Homocysteine and coronary heart disease: meta-analysis of MTHFR case-control studies, avoiding publication bias. PLoS Med. 2012;9(2):e1001177.

117. Smith AD. The worldwide challenge of the dementias: a role for B vitamins and homocysteine? Food Nutr Bull. 2008;29(Suppl 1): 143-172. 
118. Smith AD, Smith SM, De Jager CA, et al. Homocysteine-lowering by $\mathrm{B}$ vitamins slows the rate of accelerated brain atrophy in mild cognitive impairment: a randomized controlled trial. PLoS One. 2010;5(9):e12244.

119. Beard RS, Bearden SE. Vascular complications of cystathionine $\beta$-synthase deficiency: future directions for homocysteine-to-hydrogen sulfide research. Am J Physiol Heart Circ Physiol. 2011;300(1): H13-H26.

120. Finkelstein JD, Martin JJ. Homocysteine. Int J Biochem Cell Biol. 2000;32(4):385-389.

121. Kraus JP, Janošik M, Kožich V, et al. Cystathionine $\beta$-synthase mutations in homocystinuria. Hum Mutat. 1999;13(5):362-375.

122. Mudd SH, Skovby F, Levy HL, et al. The natural history of homocystinuria due to cystathionine $\beta$-synthase deficiency. Am J Hum Genet. 1985;37(1): 1 .

123. Skovby F, Gaustadnes M, Mudd SH. A revisit to the natural history of homocystinuria due to cystathionine $\beta$-synthase deficiency. Mol Genet Metab. 2010;99(1):1-3.

124. d'Emmanuele di Villa Bianca R, Mitidieri E, Di Minno MN, et al. Hydrogen sulphide pathway contributes to the enhanced human platelet aggregation in hyperhomocysteinemia. Proc Natl Acad Sci U SA. 2013;110(39):15812-15817.
125. Ingenbleek Y, McCully KS. Vegetarianism produces subclinical malnutrition, hyperhomocysteinemia and atherogenesis. Nutrition. 2012;28(2):148-153.

126. Muda P, Kampus P, Zilmer M, et al. Homocysteine and red blood cell glutathione as indices for middle-aged untreated essential hypertension patients. J Hypertens. 2003;21(12):2329-2333.

127. Budoff MJ, Takasu J, Flores FR, et al. Inhibiting progression of coronary calcification using Aged Garlic Extract in patients receiving statin therapy: a preliminary study. Prev Med. 2004;39(5): 985-991.

128. Yeh YY, Yeh SM. Homocysteine-lowering action is another potential cardiovascular protective factor of aged garlic extract. J Nutr. 2006;136(Suppl 3):745S-749S.

129. Al-Qattan KK, Khan I, Alnaqeeb MA, Ali M. Mechanism of garlic (Allium sativum) induced reduction of hypertension in $2 \mathrm{~K}-1 \mathrm{C}$ rats: a possible mediation of $\mathrm{Na} / \mathrm{H}$ exchanger isoform-1. Prostaglandins Leukot Essent Fatty Acids. 2003;69(4):217-222.

\section{Publish your work in this journal}

Integrated Blood Pressure Control is an international, peer-reviewed open-access journal focusing on the integrated approach to managing hypertension and risk reduction. Treating the patient and comorbidities together with diet and lifestyle modification and optimizing healthcare resources through a multidisciplinary team approach constitute key features of the journal. This journal is indexed on American Chemical Society's Chemical Abstracts Service (CAS). The manuscript management system is completely online and includes a very quick and fair peerreview system, which is all easy to use. Visit http://www.dovepress.com/ testimonials.php to read real quotes from published authors. 